\title{
A multi-instrument approach to mapping the global dayside merging rate
}

\author{
G. Provan, T. K. Yeoman, M. Lester, and S. E. Milan \\ Department of Physics and Astronomy, University of Leicester, University Road, Leicester LE1 7RH, UK
}

Received: 2 April 2001 - Revised: 2 May 2002 - Accepted: 11 June 2002

\begin{abstract}
For the first time three different methods have been used to calculate the global merging rate during the same substorm growth phase. The ionospheric plasma drift was monitored by six of the Northern Hemisphere SuperDARN radars, allowing the convection pattern to be studied over $12 \mathrm{~h}$ of magnetic local time. The radars observed reconnection signatures on the dayside simultaneously with substorm signatures on the nightside. The three methods to calculate the global merging rate are: (i) the equatorward expansion of radar backscatter on the nightside, which provides an estimate of the rate of polar cap expansion, while upstream WIND measurements gave an estimate of the reconnection electric fields; (ii) the derivation of the dayside boundary normal plasma flow velocity and an estimate of the extent of the ionospheric merging gap, from radar observation of dayside reconnection; (iii) utilizing the map-potential technique to map the high-latitude plasma flow and cross polar cap potential (Ruohoniemi and Baker, 1998), allowing the global dayside merging rate to be calculated. The three methods support an extensive magnetopause $X$-line length of between $30 \pm 12 R_{E}$ and $35 \pm 15 R_{E}$ (assuming a single $X$-line and constant merging rate). Such close agreement between the different methods of calculation are unexpected, especially as the length of the magnetopause $X$-line is not well known.
\end{abstract}

Key words. Magnetospheric physics (magnetopause, cusp and boundary layers; magnetosphere - ionosphere interactions; solar-wind magnetosphere interactions)

\section{Introduction}

The two-cell convection pattern observed in the high-latitude ionosphere was initially explained by Dungey's (1961) reconnection cycle. Dungey (1961) stated that during periods of southward interplanetary magnetic field (IMF), reconnection on the dayside would lead to the creation of open magnetic flux in the Earth's polar caps (PC). This open flux would

Correspondence to: G. Provan (gp3@ion.le.ac.uk) convect over the poles and then be closed by reconnection processes on the nightside in the magnetotail. This circulation of flux was originally assumed to be a steady-state phenomenon, with the rate of creation and destruction of open flux being equal at any one instant of time. Russell (1972) sketched the ionospheric flows resulting from a non-steady substorm cycle; reconnection on the dayside and in the tail became viewed as two separate time-dependent processes resulting in non-steady plasma flow in the high-latitude ionosphere (Russell and McPherron, 1973; Siscoe and Huang, 1985; Lockwood et al., 1990).

Reconnection at the dayside magnetopause and in the tail generate ionospheric convection. Figure 1a (after Lockwood et al.; 1990, Lockwood, 1991) describes the steady-state flow driven by balanced dayside and nightside reconnection, when the polar cap boundary is stationary. The solid-line corresponds to the open/closed field line boundary and the dashed line to the dayside or nightside merging gap. $\Phi_{D}$ corresponds to the potential across the dayside merging gap, $\Phi_{N}$ to the potential across the nightside merging gap and $\Phi_{P C}$ to the cross polar-cap potential. In this paper, the cross polar cap potential is defined as the potential difference between the maximum and minimum voltages of the dawn and dusk convection cells, and all potentials will be discussed in greater detail in Sect. 4.3. Figure 1b shows the convection pattern generated by reconnection at the magnetopause alone, when the polar cap is expanding, and Fig. 1c shows the same for unbalanced nightside reconnection, with a contracting polar cap, as suggested by the expanding-contracting polar-cap (ECPC) model proposed by Siscoe and Huang (1985). Reconnection on either the dayside or the nightside influences convection at all locations within the polar cap and auroral ovals (Lockwood, 1991). Convective flow is only excited when reconnection has recently been in progress, with dayside flow responding rapidly to changes in the IMF and nightside flows to changes in the reconnection rate in the tail.

Impulsive dayside reconnection is now believed to be the primary mechanism for the transfer of magnetic flux from the Earth's magnetosheath into the magnetosphere, and episodes of such transient flux transfer are termed flux transfer events 
(a)

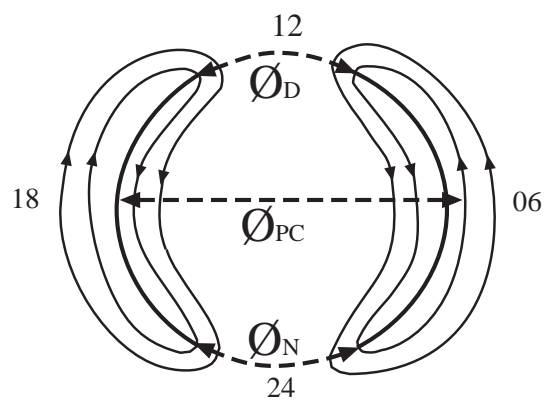

(b)

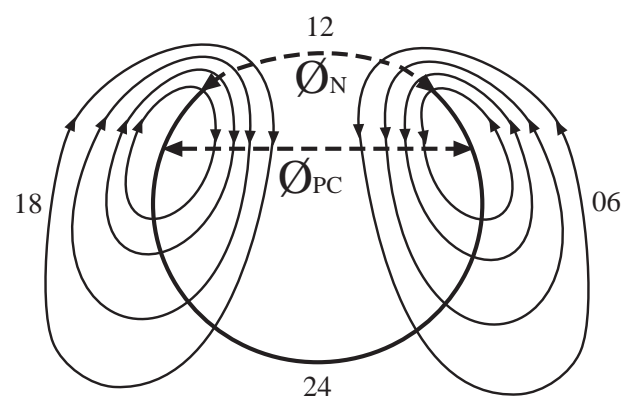

(c)

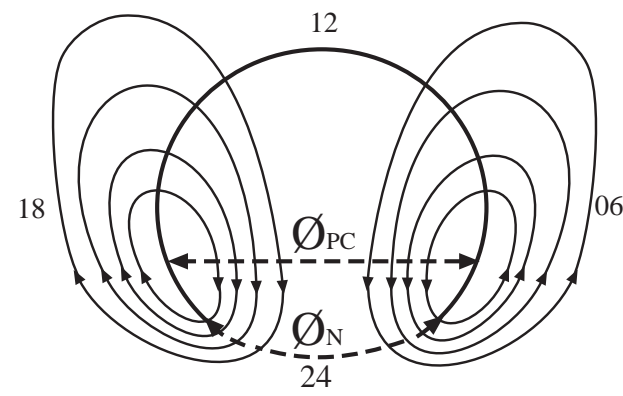

Fig. 1. (a) Ionospheric convection pattern resulting from balanced reconnection at the dayside magnetopause and in the tail. (b) Convection generated by unbalanced dayside reconnection. (c) Convection generated by unbalanced nightside reconnection (after Lockwood, 1991).

(FTEs) (Russell and Elphic, 1978, 1979). Determining the reconnection rate on the dayside, together with its counterpart on the nightside, is of primary importance when describing the dynamics of the magnetosphere/ionosphere coupled system. HF radars are now established as powerful tools in these types of study. Strong HF radar backscatter near local noon, with anti-sunward convective flows, has previously been demonstrated to be co-located with DMSP particle signatures of the cusp and poleward moving optical transients characteristic of pulsed reconnection (Yeoman et al., 1997). Neudegg et al. (1999) observed an FTE at the magnetopause with the Equator-S spacecraft, while corresponding transient plasma flows were observed in the near-conjugate polar ionosphere by the CUTLASS HF radar in Hankasalmi. Provan et al. (1998) have previously used data from the Hankasalmi radar to perform a detailed study of the dynamics and extent of pulsed anti-sunward moving transient features, detected poleward of a convection reversal boundary (CRB) at high-latitudes in the CUTLASS field-of-view (f-o-v.). These pulsed ionospheric flows (PIFs) had an average recurrence rate of 7 to $8 \mathrm{~min}$, which is close to the average recurrence rate of FTEs, as first reported by Rijnbeek et al. (1984). The PIFs were demonstrated to be the ionospheric signatures of FTEs created at the footprint of newly-reconnected field lines as they are being pulled anti-sunward by the magnetosheath flow (Provan et al., 1998; Provan and Yeoman, 1999; Neudegg et al., 1999, 2000). McWilliams et al. (2000) performed a statistical study on the occurrence of PIFs as observed by the CUTLASS HF radars. The PIFs were found to be grouped in the vicinity of the radar signature of the cusp footprint with a very similar repetition rate to the FTEs at the magnetopause, and two-thirds occurred when the IMF had a southward component, a strong indication that they are reconnection related phenomena.

HF radars studies have investigated the spatial and temporal development of ionospheric conductivities and electric field during the three phases of geomagnetic substorms; growth phase, expansion phase and recovery phase. (Morelli et al., 1995; Yeoman and Pinnock, 1996; Yeoman and Lühr, 1997; Shand et al., 1998; Lewis et al., 1997, 1998a, 1998b; Yeoman et al., 1999; Lester, 2000). The substorm growth phase is an interval of overall magnetic flux addition to the polar cap. Lewis et al. (1997) observed a small isolated substorm with the Halley HF radar; its growth phase was characterized by a systematic equatorward motion of the radar backscatter, thought to correspond to an equatorward motion of the expanding auroral oval. Expansion phase onset is characterized by a rapid enhancement and large-scale expansion of the nightside auroral activity, which is caused by the enhanced particle precipitation. Many studies have reported a lack of HF radar data immediately following the expansion phase onset, due to the absorption of radio waves in the ionosphere (e.g. Lewis et al., 1997; Yeoman and Lühr, 1997; Lester, 2000). The ECPC model predicts that reconnection of open magnetic flux in the geomagnetic tail, such that nightside reconnection exceeds the dayside reconnection, is expected to occur at or after expansion phase onset. The main consequence of this would be the stimulation of flows on the nightside and the contraction of the polar cap. If the reconnection takes place in a bursty fashion, then the stimulated flows would most likely appear to be bursty in the same way as dayside ionospheric convection responds to flux transfer events (e.g. Yeoman and Lühr, 1997; Lester, 2000).

HF radars have also proved to be a successful technique for investigating global convection patterns. Ruohoniemi et al. (1989) presented a study on the mapping of the large-scale high-latitude plasma convection with coherent HF radars using beam-swinging techniques. Subsequently, Ruohoniemi and Baker (1998) described an improved method of deriving large-scale convection maps based on all the available velocity data, as detected by the HF radar of the Super Dual Auroral Radar Network (SuperDARN), thus, deriving the 


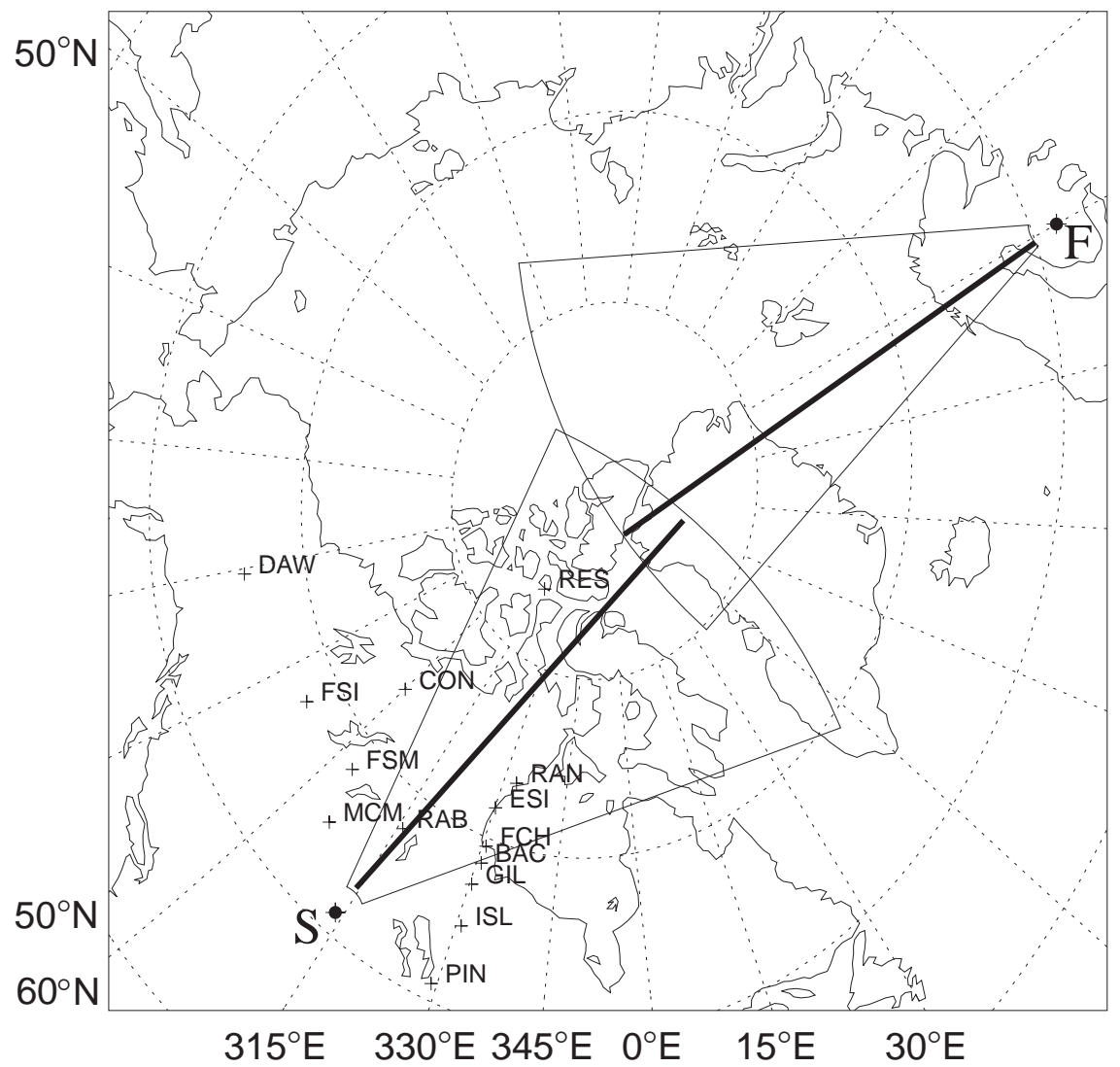

Fig. 2. The fields-of-view of the Finland $(\mathrm{F})$ and Saskatoon $(\mathrm{S})$ radars, and the locations of the CANOPUS magnetometer stations. The two black lines highlight the position of beam 4 of the Finland radar, and beam 5 of the Saskatoon radar. cross polar-cap potential. Taylor et al. (1996) studied the dynamic behaviour of the northern polar cap area using an Assimilative Mapping of Ionospheric Electrodynamics (AMIE) procedure to derive global electric potential patterns for the Northern Hemisphere, while Taylor et al. (1998a, b) did the same using the SuperDARN radars. The authors were particularly interested in the changes in the polar cap area and ionospheric convection as a response to changes in the IMF and solar wind conditions.

On 16 September 1998, all the Northern Hemisphere SuperDARN radars were run in normal-resolution mode, allowing the high-latitude ionosphere to be studied over more than $12 \mathrm{~h}$ of magnetic local time. The extensive radar network has allowed the first HF radar observations of reconnection signatures on the dayside, detected simultaneously with substorm signatures on the nightside. We have studied data from all the Northern Hemisphere radars for this day, using the JHU/APL map-potential technique (Ruohoniemi and Baker, 1998) to map the global ionospheric convection pattern. A special emphasis has been placed on the line-of-sight velocities observed by the Hankasalmi and Saskatoon radars, the fields-of-view (f-o-v) of these radars being separated by as much as $\sim 12 \mathrm{~h}$ of MLT. We study a 4 -h period during this day when Hankasalmi observes the ionospheric response to reconnection on the dayside, while Saskatoon observes ionospheric substorm signatures on the nightside. The interplanetary magnetic field (IMF), as measured by the WIND spacecraft, has a strong positive $B_{y}$ and predominately negative $B_{z}$ components. Using data from the Hankasalmi and Saskatoon radars, both separately and in combination, we have been able to infer the global merging rate, and the length and electric field of the merging gap, using three different methods of calculation. All calculations assume a uniform merging rate and a single $X$-line.

\section{Instrumentation}

The ionospheric convection velocities presented in detail in this study are provided by the SuperDARN Hankasalmi and the Saskatoon HF radars, both elements of the international SuperDARN chain of HF radars (Greenwald et al., 1995). Each radar of the system is a frequency agile $(8-20 \mathrm{MHz})$ radar, routinely measuring the line-of-sight (1-o-s) Doppler velocity and spectral width of, and the backscattered power from, ionospheric plasma irregularities. The radars each form 16 beams of azimuthal separation $3.24^{\circ}$. Each beam is gated into 75 range bins, each of length $45 \mathrm{~km}$ in standard operations, when the dwell time for each beam is $7 \mathrm{~s}$, giving a full 16 beam scan, covering $52^{\circ}$ in azimuth and over $3000 \mathrm{~km}$ in range (an area of over $4 \times 10^{6} \mathrm{~km}^{2}$ ), every $2 \mathrm{~min}$. In this paper, this data set is supplemented by magnetometer data from the CANOPUS array. Figure 2 shows the fields-of-view of the Hankasalmi (F) and Saskatoon (S) radars in geomagnetic coordinates, as well as the location of the CANOPUS magnetometer stations. The position of beam 4 (beam 5) of the 


\section{IMF Bz component, 16/09/98}

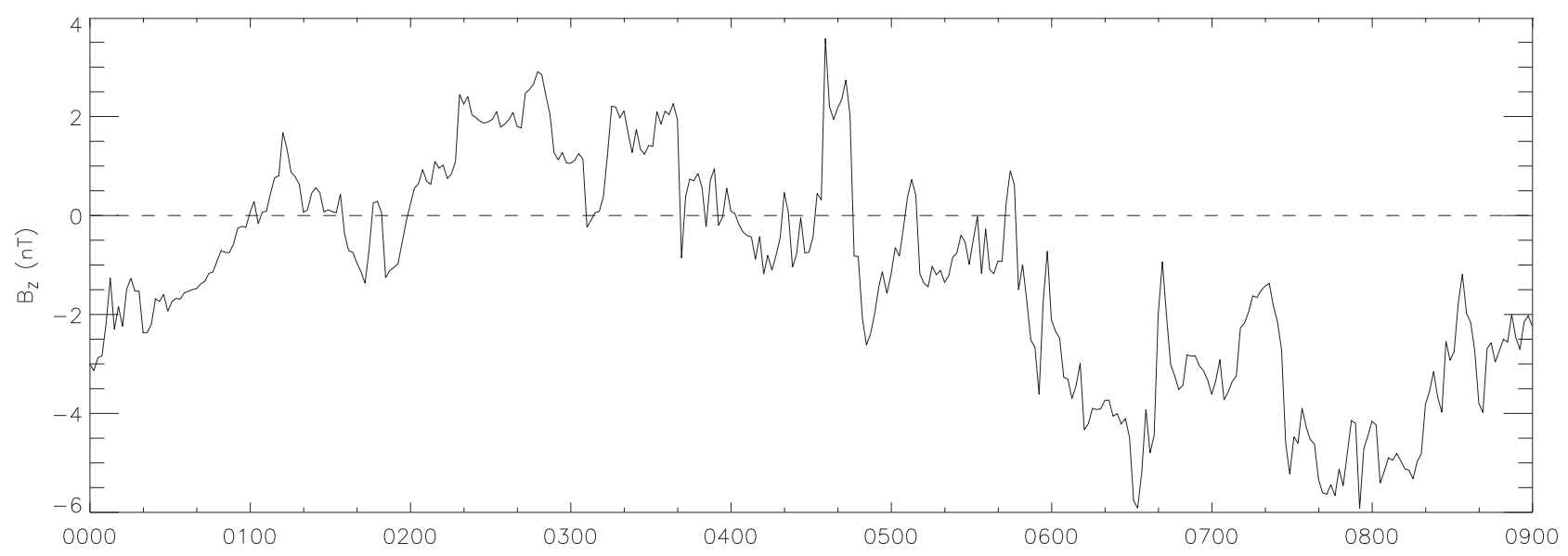

Fig. 3. The IMF $B_{z}$ component measured by the WIND spacecraft for the period 00:00 to 09:00 UT. A 75-min lag time has been added onto the time scale of the plot, representing the delay between the IMF being observed by the satellite and when it impinges on the magnetopause.

Hankasalmi (Saskatoon) radar is marked on the figure with a solid black line. Upstream IMF data from the WIND satellite (Lepping et al., 1995) are also included in this study. Low altitude particle precipitation data are provided by the DMSP F13 spacecraft. Hardy et al. (1984) have provided detailed information concerning the detectors.

The map-potential technique (developed by JHU/APL) derives the large-scale ionospheric convection maps from l-o-s velocities observed by the entire network of Northern Hemisphere SuperDARN (SD) radars (Ruohoniemi and Baker, 1998). The ionospheric convection pattern is calculated by a mathematical fitting technique using all the available lineof-sight measurements (Ruohoniemi and Baker, 1998). The solution is constrained by folding in information from a statistical model (Ruohoniemi and Greenwald, 1996), keyed to the IMF conditions. For this study IMF information is given by the WIND satellite. From the global electric field it is possible to calculate the energy input to the Earth's ionosphere from dayside and nightside reconnection processes, the cross-polar cap potential, and to deduce parameters vital to global models.

\section{Data presentation}

\subsection{IMF observations}

Figure 3 shows the $B_{z}$ component of the IMF as measured by the WIND satellite for the time interval 00:00 to 09:00 UT. At 00:00 UT the satellite was located near $X_{g s m}=182 R_{E}, Y_{g s m}=4.7 R_{E}$ and $Z_{g s m}=-11.6 R E . \mathrm{A}$ $75 \pm 5$ min lag-time between when the IMF is observed by the satellite and when it impinges on the subsolar magnetopause has been calculated using the method outlined by Lester et al. (1993); this time has been added onto the time scale of the plot. In this paper, we will be studying primarily the interval
04:30 to 08:30 UT. During this time, the IMF $B_{z}$ component was predominantly negative, while the IMF $B_{y}$ component was entirely positive.

\subsection{Dayside radar observations}

Figure $4 \mathrm{a}$ shows a latitude-time-velocity plot for beam 4 of Hankasalmi between 04:30 and 08:30 UT on 16 September 1998. The Doppler velocity is colour-coded with positive (blue) velocities, indicating motion towards the radar and negative (red/yellow) velocities indicating motion away from the radar, while grey indicates backscatter from the ground. Figure $4 \mathrm{~b}$ presents the spectral width for the same period. The spectral widths are colour-coded with red representing the greatest spectral widths, and blue representing the smallest. Hankasalmi beam 4 detects ionospheric backscatter between magnetic latitudes of $75.5^{\circ}$ to $85^{\circ}$ (AACGM coordinates, Baker and Wing, 1989). At high-latitude the radar observes high velocities moving anti-sunward. At lower latitudes lower velocities are observed, mainly moving antisunward. These high velocity anti-sunward backscatter are in general associated with a high spectral width (between 250 and $400 \mathrm{~m} / \mathrm{s}$ ). After 06:30 individual PIF signatures are clearly identifiable, these poleward transient features are observed at high-latitude and are characterized by large antisunward velocities and large spectral widths. Before 06:30 individual PIFs are harder to identify, but poleward moving features and fluctuations in anti-sunward moving backscatter are clearly observed.

\subsection{DMSP observations}

Low altitude particle precipitation data are provided here using the DMSP F13 spacecraft. In Fig. 5 DMSP measurements of precipitating electrons and ions are presented for the interval 08:05 to 08:08:30 UT for 16 September 1998 . 

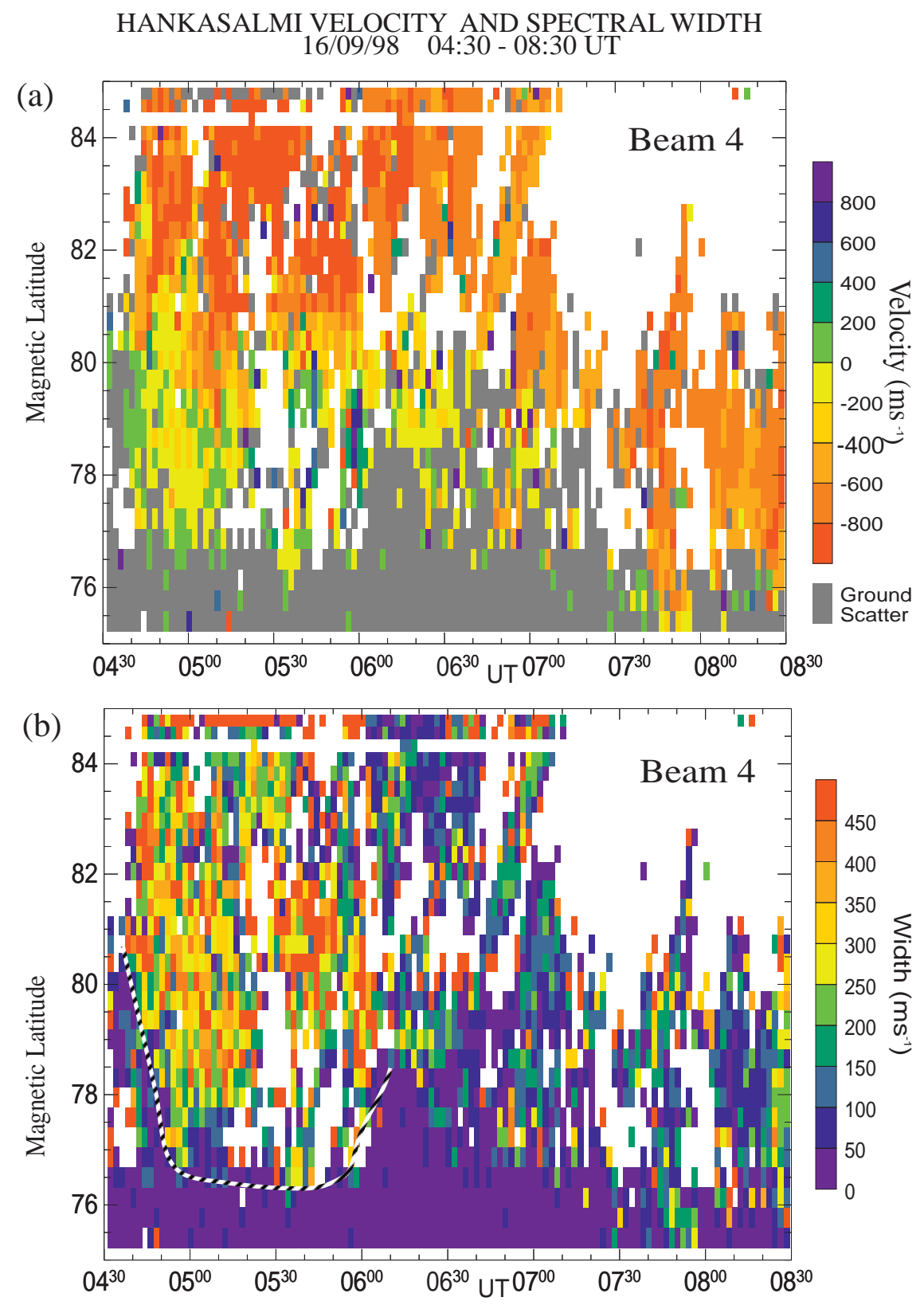

Fig. 4. (a) The latitude-time-velocity plot for the Finland radar, 16 Sept. 1998, 04:30 to 08:30 UT. The Doppler velocity is colour-coded with positive (blue) velocities, indicating motion towards the radar and negative (red/yellow) velocities indicating motion away from the radar, while grey indicates backscatter from the ground. (b) The latitude-time-spectral width plot for the Finland radar, 16 Sept. 1998 , 04:30 to 08:30 UT. The spectral width is colour-coded, with red representing the greatest spectral widths and blue representing the smallest.

During this interval, the spacecraft flies from $75.9^{\circ}$ to $68.9^{\circ}$ magnetic latitude. Between $\sim 08: 05$ and $\sim 08: 06$ UT there is an enhanced flux of low energy electrons, clear signatures of open field lines. There is also an increase in the flux of energetic ions, and some distinctive dispersed ion precipitation features. In these features the ion energy is seen to increase as latitude decreases, and there is possibly a "step" within the feature at $\sim 08: 06 \mathrm{UT}$; such a feature has previously been named a cusp ion step (Lockwood and Davis, 1996). These features are characteristic of bursts of cusp precipitation, associated with transient magnetopause reconnection for a southward directed IMF $B_{z}$. At 08:06 UT there is an increase in the number of precipitating hot electrons; these are observed until 08:08:20 UT and are indicative of closed, auroral zone field lines. Thus, the open/closed field line boundary is identified at 08:06 UT, at $74.5^{\circ}$ MLAT. Three lines (labelled 1 to 3 ) have been added to Fig. 5. Line 1 corresponds to the position of the spacecraft at 08:05:20 UT when the dispersed ion signatures are first observed. Line 2 identifies the spacecraft position at 08:06 UT when the open/closed field line boundary is detected in the electron data, and Line 3 corresponds to the spacecraft position at 08:08:20 UT after which time no more precipitating hot electrons are observed.

Figure 6 presents a polar plot of the 1-o-s velocity observed by the Hankasalmi radar at 08:06 UT, as a function of magnetic latitude and magnetic local time. The Hankasalmi radar is located at approximately 10:30 MLT and is detecting backscatter between 08:00 and 14:30 MLT at $\sim 80^{\circ}$ latitude. 


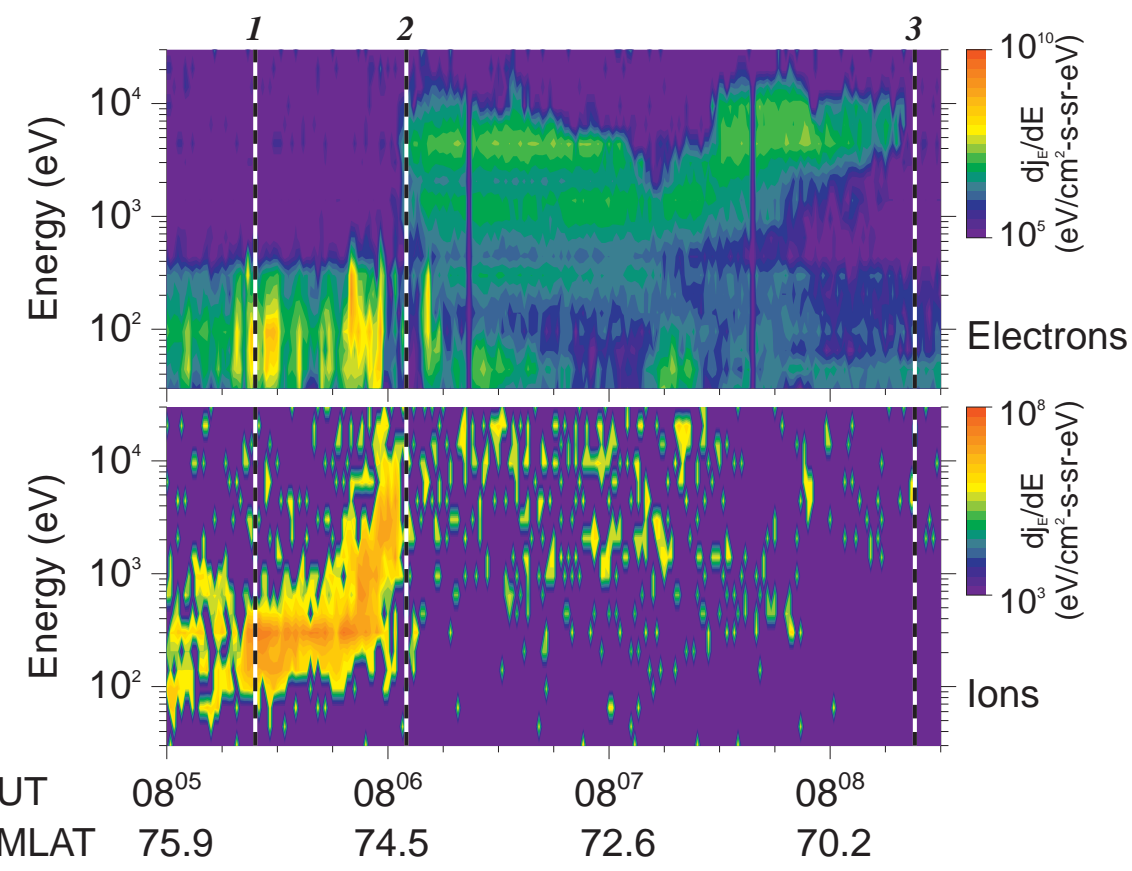

Fig. 5. DMSP measurements of the fluxes of precipitating electrons and ions, 16 September 1998, 08:05 to 08:08:30 UT. The lines labelled 1, 2 and 3 show the position of the spacecraft at 08:05:20, 08:06 and 08:08:20, respectively.

\section{MLT}

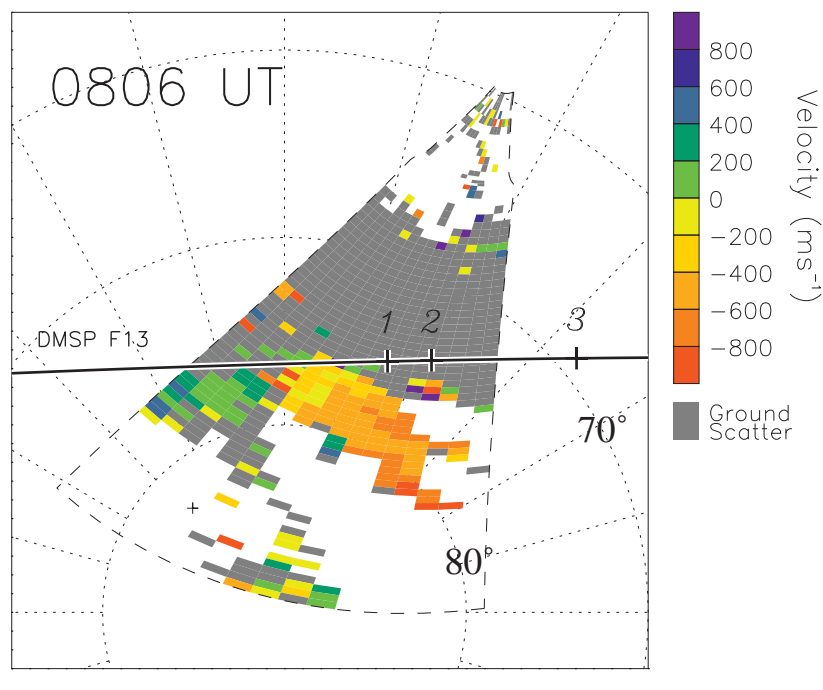

Fig. 6. Polar plot of the 1-o-s velocity observed by the Hankasalmi radar at 08:06 UT, as a function of magnetic latitude and magnetic local time. Overlaid is a black line showing the footprint of the DMSP spacecraft. The ticks labelled 1, 2 and 3 shows the position of the spacecraft at 08:05:20, 08:06 and 08:08:20, respectively (as in Fig. 5).

The Doppler velocity is colour-coded as before, with positive (blue) velocities, indicating motion towards the radar and negative (red/yellow) velocities indicating motion away from the radar, while grey indicates backscatter from the ground. The scan corresponds to the passage of the footprint of the DMSP satellite over the center of the radar field-of-view in AACGM coordinates. The footprint of the DMSP space- craft, calculated using AACGM coordinates at $850 \mathrm{~km}$ altitude, is indicated by a line, with three ticks marks labelled 1,2 and 3, which correspond to the times of the three lines added to Fig. 5. In studying Fig. 6, the open/closed field line boundary (tick mark 2 ) is located about $\sim 2^{\circ}$ equatorward of the equatorward edge of the ionospheric backscatter. The line-of-sight velocity during this scan shows flow to be predominantly away from the radar. In the easternmost far ranges, very low line-of-sight velocities flows are observed, whereas the westernmost far ranges detect the strongest velocities. This suggests that the anti-sunward flow has a westward (dawnward) component, as expected for high-latitude convection under IMF $B_{z}$ negative, $B_{y}$ positive conditions, as were measured upstream by the WIND spacecraft.

\subsection{Nightside radar observations}

Figure 7 presents the LTV plot for beam 5 of the Saskatoon radar, 04:30 to 08:30 UT. At 04:30 UT, Saskatoon is located at 21:00 MLT and observes backscatter between $\sim 20: 30$ and $\sim$ 02:00 MLT. Between 04:35 and 05:50 UT, the equatorward boundary of the ionospheric backscatter observed by beam 5 appears to move in a general, equatorward direction, moving from a initial latitude of $\sim 78^{\circ}$ to a latitude of $\sim 71^{\circ}$. At 06:13 UT (marked on the plot with a black dashed line), there is a general loss of backscatter. Such equatorward propagation of backscatter followed by a loss of backscatter has previously been observed by Lewis et al. (1997, 1998a, b) and Yeoman et al. (1999). These authors identified the equatorward motion of backscatter with the substorm growth phase, during which newly-opened magnetic flux is added to the polar cap on the dayside. The loss of HF backscatter occurred at the onset of the substorm expansion phase, as has previ- 
SASKATOON L-O-S VELOCITY AND CANOPUS MAGNETOMETER, 16/09/98

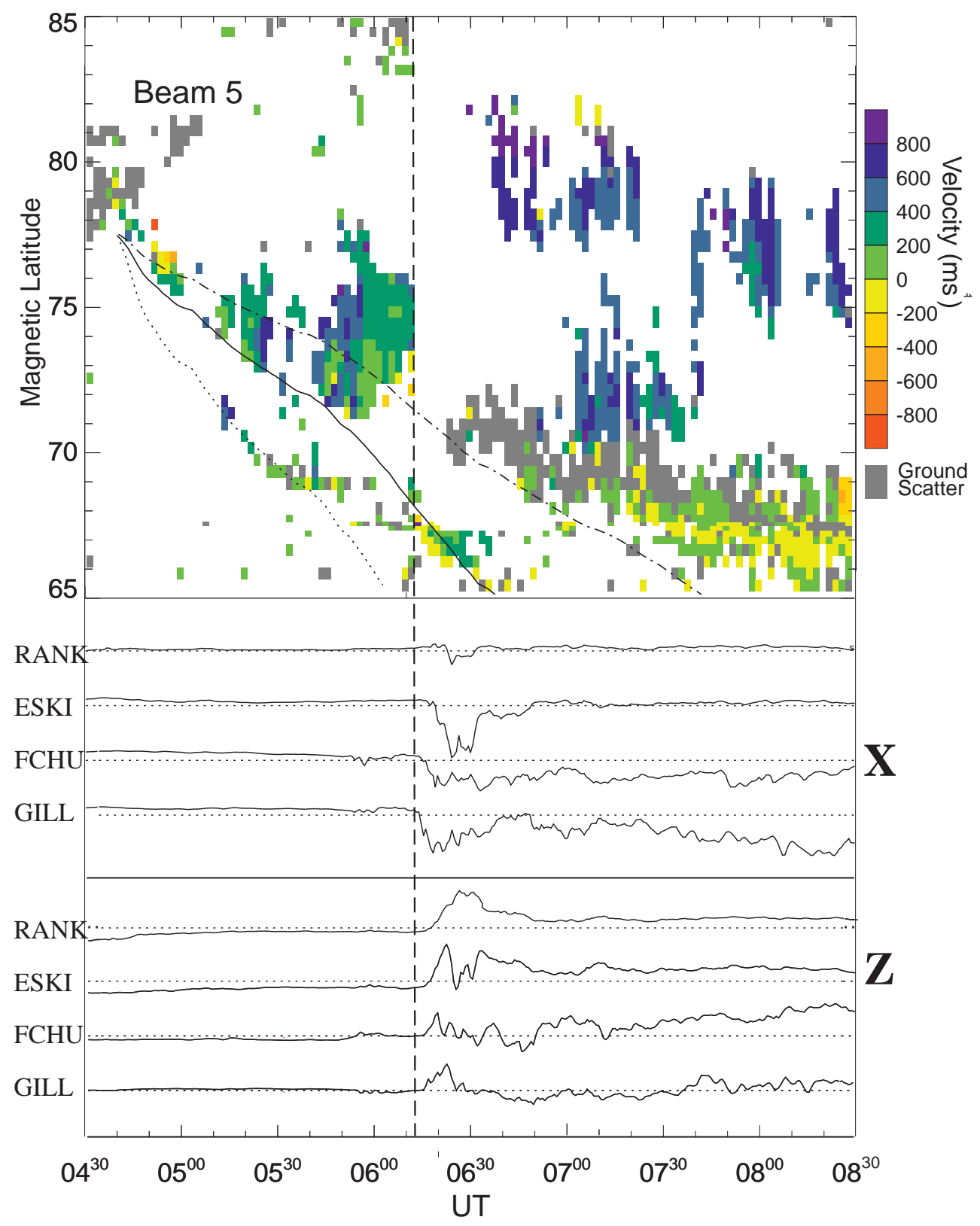

Fig. 7. LTV plot for beam 5 of the Saskatoon radar, 04:30 to 08:30 UT. Overlaid is a black line showing the model calculations of where the equatorward boundary of the radar backscatter should lie, assuming an $X$-line length of $35 R_{E}$, and a constant offset of $4^{\circ}$ from the polar cap boundary. The dot-dashed line is the model calculation of the location of radar backscatter for a latitudinal offset of $0^{\circ}$ and a $X$-line length of $20 R_{E}$, while the dashed line models the location of radar backscatter for a latitudinal offset of $8^{\circ}$ and an $X$-line length of $50 R_{E}$. The bottom two panels of the figure show the $X$ and $Z$ components of 4 magnetometers of the CANPOUS magnetometer array.

ously been reported by Milan et al. (1996), Yeoman and Lühr (1997) and Yeoman et al. (1999).

The bottom two panels of Fig. 7 show the $X$ and $Z$ components of 4 magnetometers of the CANPOUS magnetometer array. The stations are presented in order of decreasing latitude from the top, with RANK (highest latitude), ESKI and FCHU all located within the Saskatoon radar f-o-v, and GILL (lowest latitude) located just outside the radar's f-o-v.
From the plots we can see that the time of the loss of radar backscatter occurs almost simultaneously with the initial observations of strong negative bays in the $X$-component and positive perturbation in the $Z$-component, both moving to higher latitudes with time. These are indicative of an enhanced substorm westward electrojet located equatorward of the magnetometer stations and propagating over them as the substorm expansion phase progresses. Studying this interval 


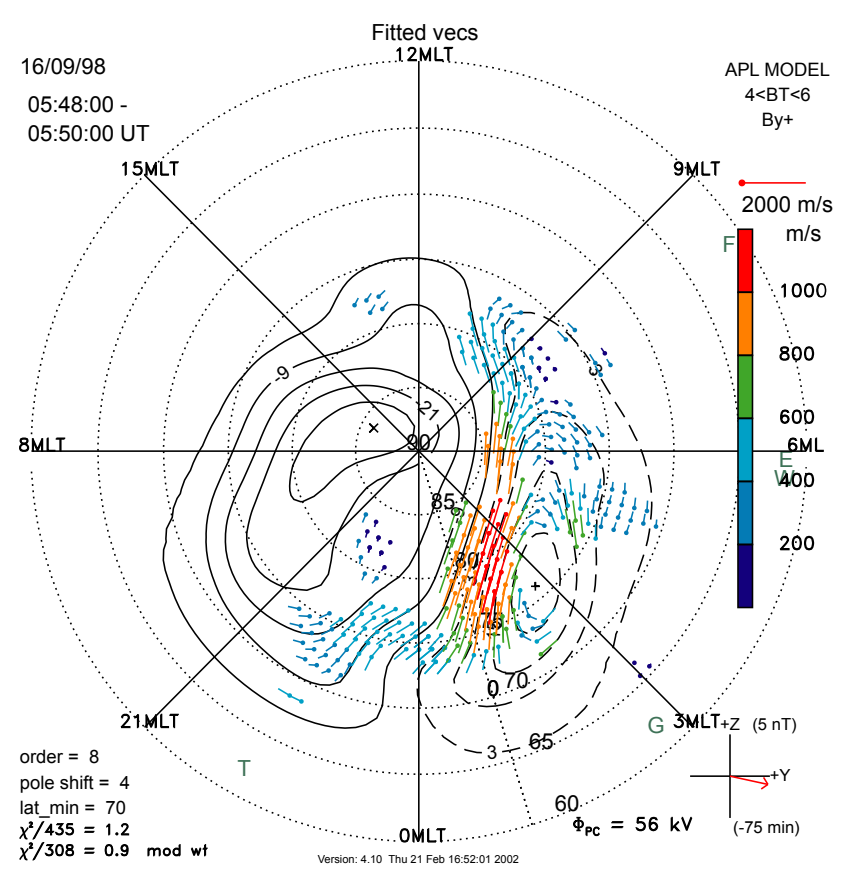

Fig. 8. Solution for the global convection pattern calculated with the map-potential technique using 1-o-s velocity data from all 6 of the Northern Hemisphere SuperDARN radars, 05:48 to 05:50 UT. The electrostatic potential was expanded to an order of $L=8$ (Ruohoniemi and Baker, 1998), and the flow was assumed to be centered $4^{\circ}$ from the pole. The low-latitude limit of the convection zone was assumed to be $70^{\circ}$.

with POLAR UVI data (not presented) shows the onset of the expansion phase to be at 06:14 UT.

\subsection{The (JHU/APL) map-potential technique}

We have presented two separate pieces of evidence of ionospheric signatures of dayside reconnection processes as observed by two SuperDARN radars, one observing backscatter near the dayside cusp and the other in the pre-midnight sector. Between 04:35 to 06:13 UT, the Hankasalmi radar observes ionospheric signatures of dayside reconnection, while the Saskatoon radar observes signatures of the growth of the polar cap, demonstrating that the dayside reconnection rate exceeds the nightside rate. Next, we investigated the large-scale ionospheric convection, using 1-o-s velocity data from all the Northern Hemisphere SuperDARN radars, together with the JHU/APL map-potential data visualisation technique (Ruohoniemi and Baker, 1998).

The map-potential technique was used to derive the solution for the global convection pattern during the entire interval when dayside reconnection processes were observed. From the global patterns, a value of the cross polar-cap potential was derived and will be used to infer a value of potential across the dayside merging gap (Sect. 4.3). One of these global convection patterns is presented in Fig. 8. The pattern is calculated using 1-o-s velocity data from all six of the Northern Hemisphere SuperDARN radars, for the scan start- ing at 05:48 UT. The electrostatic potential was expanded to an order of 8 (Ruohoniemi and Baker, 1998), and the flow was assumed to be centered $4^{\circ}$ from the pole. The low-latitude limit of the convection zone was assumed to be $70^{\circ}$. The solution was constrained by folding in information from a statistical model (Ruohoniemi and Greenwald, 1996), keyed to the IMF observations. The IMF measurements were given by the WIND satellite, and a $75 \pm 5$ min delay time was considered between the IMF observations at the WIND satellite and its impingement on the dayside magnetopause. The solid (dotted) contours are associated with negative (positive) values of the electrostatic potential, and the contour interval is $6 \mathrm{kV}$. The cross polar cap potential inferred from this solution is $56 \mathrm{kV}$, and the reduced chi-square for the fitting is 1.2 . The velocity of the fitted vectors are coded both in colour (blue indicating the slowest velocities, red the fastest) and in the length of the vectors.

Figure 8 shows continuous data coverage of plasma flow, from the dayside convection throat over the polar cap and into the nightside convection throat. The fastest velocities appear to be in the central polar cap. A few vectors centered at a latitude of $\sim 70^{\circ}$ in the dawn sector flow from the nightside to the dayside, thus, indicating return flow at these low-latitudes. There are far fewer vectors observed for the dusk cell than for the dawn cell, thus, the depicted dusk cell depends more on input from the statistical model than the dawn cell.

\section{Discussion}

Pulsed flow signatures have been observed in dayside data from the Hankasalmi HF radar. In the past PIF signatures have been observed at high-latitude in the SuperDARN radars f-o-v. These PIFs were associated with high l-o-s velocity and a large spectral width, and were moving in an anti-sunward direction. PIFs are easier to identify with highresolution data, created when the radars operate in special scan modes which involves scanning on certain beams more frequently than every $2 \mathrm{~min}$. But such special scan data are not suitable when attempting to do a global study, when it is not viable to sacrifice spatial resolution for temporal resolution. Individual pulsed flows are observed by the Hankasalmi radar between 06:30 and 08:30 UT, and can be clearly identified as the ionospheric signatures of pulsed reconnection at the dayside magnetopause, especially when seen in conjunction with the cusp ion steps detected in the DMSP data. Individual PIFs are harder to identify before 06:30 UT, but the high-latitude, high velocity, high spectral width backscatter signifies dayside reconnection with the newly-reconnected field line being pulled anti-sunward by the magnetosheath flow at high speed.

Signatures of a substorm growth phase and the expansion phase onset are observed on the nightside, characterized by an equatorward motion of the radar backscatter followed by a sudden lack of backscatter. Simultaneously, PIFs are being observed on the dayside. We are interested in using both the 
dayside and nightside observations, together with data from other instruments, to estimate the length of, and the electric field along, the dayside merging gap. Such a comparison of different methods of calculating the length of the dayside merging gap and its electric field has yet to be done. In order to investigate this we have used HF radar observations of PIFs, the map-potential technique, and modelled the polar cap boundary, using the method of Lewis et al. (1998b). We discuss each of these in turn below.

4.1 Measuring the length and electric field of the dayside merging gap using nightside observations

The LTV plots from Saskatoon presented in Fig. 7 show a clear signature of the substorm growth phase occurring between 04:35 and 06:13 UT. The characteristic signature of the substorm growth phase is a systematic equatorward motion of the radar backscatter, thought to correspond to an equatorward motion of the structured precipitation in the auroral oval. At 06:13 UT there is a general lack of backscatter; such loss of backscatter has previously been identified at the onset of a substorm expansion phase (e.g. Milan et al., 1996; Yeoman and Lühr, 1997).

During the substorm growth phase, the equatorward boundary of the radar backscatter moved equatorward between 04:35 and 05:50 UT, with an average velocity of $160 \pm 30 \mathrm{~m} / \mathrm{s}$. We assume the position of the equatorward edge of the radar backscatter to be directly related to, but not necessarily colocated with, the position of the polar cap boundary. Using a model of the Feldstein oval for $Q=2$ conditions, it was estimated that the oval would move equatorwards with a velocity of $20 \mathrm{~m} / \mathrm{s}$ during this time as a consequence of the local time progression of the radar. So the polar cap boundary moved equatorward with a velocity of $140 \pm 30 \mathrm{~m} / \mathrm{s}$ during this time due to the addition of flux to the polar cap. Using a beam-swinging technique (Villain et al., 1987), which assumes spatial uniformity across the Saskatoon radar f-o-v, the average equatorward and azimuthal components of the plasma flow were measured during the same substorm growth phase interval (04:35 to 05:50 UT). The average equatorward component of the plasma flow velocity was $130 \pm 60 \mathrm{~m} / \mathrm{s}$ during the substorm growth phase period. Within experimental errors these velocities are equal and would suggest that, in this instance, the polar cap boundary is adiaroic (Siscoe and Huang, 1985), that is there is no plasma flow relative to it, with the convection of the ionospheric plasma over the polar cap being directly related to the expansion of the polar cap boundary. Cowley and Lockwood (1992) and Lockwood and Cowley (1992, and see references within) have previously suggested that the polar cap boundary can be idealized as such an adiaroic boundary which can only be perturbed by the creation (due to dayside reconnection) or the destruction (due to nightside reconnection) of open flux, leading to the expansion or contraction of the polar cap area.

We have attempted to estimate the reconnection electric field and length of the dayside merging gap, following the technique of Lewis et al. (1998b), also described by Yeoman et al. (1999). In this method the reconnection electric field is derived using the solar wind data (Hill, 1975; Sonnerup, 1974), while the variation in the equatorward edge of the backscatter is used to provide an estimate of the expansion of the polar cap. Faraday's law of the rate of flux addition states that:

$B_{P} \frac{d A_{P C}}{d t}=\Phi_{D}^{\prime}-\Phi_{N}^{\prime}$,

where $d A_{P C} / d t$ is the rate of change of the polar cap area and $B_{P}$ is the polar magnetic field at ionospheric altitudes, $\sim 5 \times 10^{-5}$ T. $\Phi_{D}^{\prime}$ is the potential across the dayside merging gap in its own rest frame, which is equal to the dayside reconnection electric field multiplied by the length of the dayside merging gap, and $\Phi_{N}^{\prime}$ is the potential across the nightside merging gap in its own rest frame, which is equal to the nightside reconnection electric field multiplied by the length of the nightside merging gap.

Assuming, as Lewis et al. (1998b) did, that there is no nightside magnetotail reconnection $\left(\Phi_{N}^{\prime}=0\right)$, Faraday's law can be re-written as

$B_{P} \frac{d A_{P C}}{d t}=E L$,

where $L$ is the length of the magnetopause $X$-line and $E$ is the electric field along it. Thus, knowing the electric field from the solar wind data, and the rate of polar cap expansion from the radar backscatter, Eq. (2) can be used to estimate the length of the dayside merging gap.

We assume a circular polar cap and a constant offset between the equatorward boundary of radar backscatter and the polar cap boundary. There is no suitable nightside DMSP data available, so we have assumed that the offset between the polar cap boundary and the equatorward edge of the radar backscatter remains constant at $4 \pm 4^{\circ}$ throughout (this is identical to the offset assumed by Lewis et al., 1998b). Holzworth and Meng (1975) suggested a latitudinal offset when modelling the auroral oval. The offset is suggested to represent an approximation of the latitudinal extent of the auroral oval, with the equatorward boundary of the auroral oval being co-located close to the equatorward boundary of the backscatter, while the poleward boundary of the auroral oval is located in close proximity to the polar cap.

We estimate a $75 \pm 5$ min time delay between when the IMF is observed by the spacecraft and when it impinges on the subsolar magnetopause. Overlaid on Fig. 7 is a solid black line showing the model calculation of the location of the equatorward edge of radar backscatter. A visual inspection of the data has been performed to determine that this model calculation best fits the observed location of radar backscatter. The calculation is parameterized by an assumed dayside magnetopause $X$-line length of $35 \pm 15 R_{E}$, although this might be an overestimation, as field line stretching in the magnetotail is a factor not included in this model (Yeoman et al., 1999). The lines on either side of the solid black lines show the extremes of the error calculation; the 
HANKASALMI AND ICELAND WEST, 16/09/98, 08:10 UT

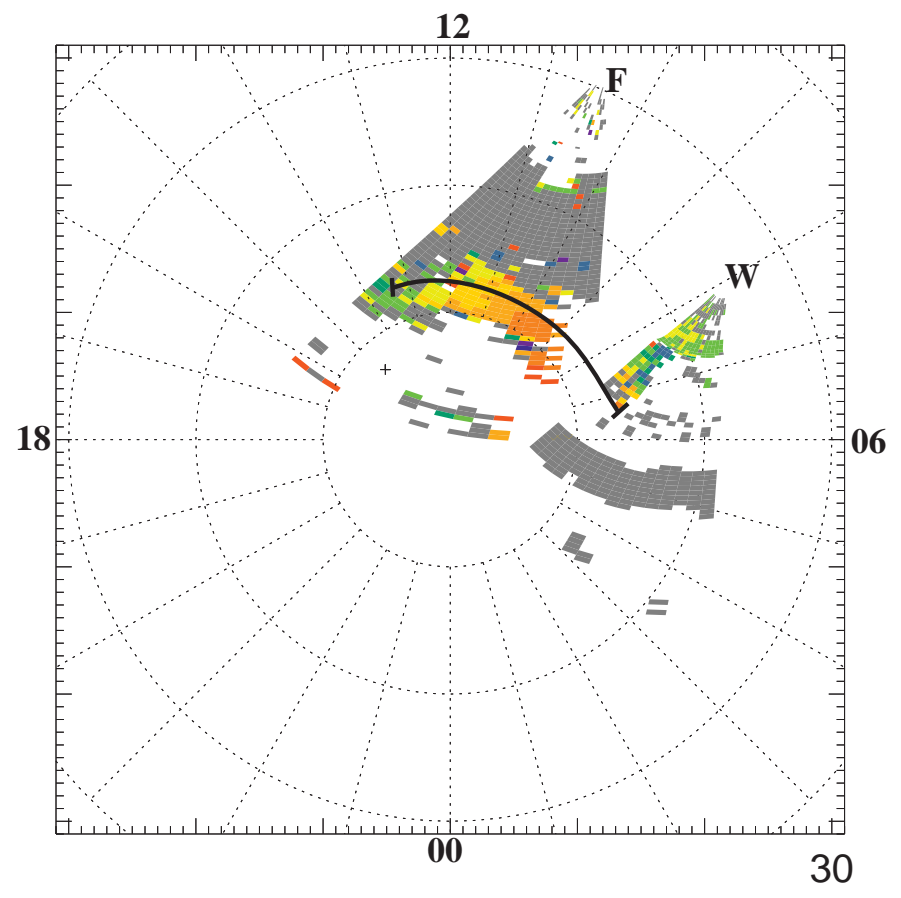

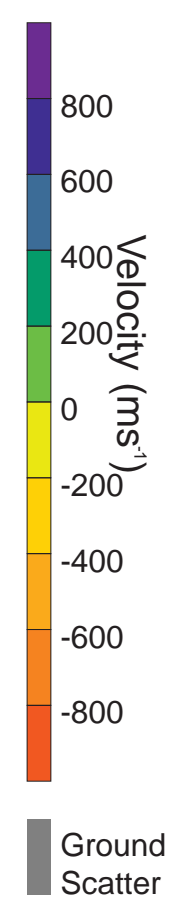

Fig. 9. Polar plot of the 1-o-s velocity for the Hankasalmi and Iceland West radars for 08:10 UT. The overlaid black line shows the estimated extent of the merging gap footprint. dot-dashed line is the model calculation of the location of radar backscatter for a latitudinal offset of $0^{\circ}$ and a $X$-line length of $20 R_{E}$, while the dashed line is for a latitudinal offset of $8^{\circ}$ and an $X$-line length of $50 R_{E}$. The derived $X$ line length of $35 \pm 15 R_{E}$, compares with an average value of $12 R_{E}$ previously calculated by Lewis et al. (1998), and of an $X$-line length of $27 R_{E}$ calculated by Yeoman et al. (1999). $35 R_{E}$ covers approximately $10 \mathrm{~h}$ of MLT at the magnetopause boundary, according to the Tsyganenko 89 (Tsyganenko, 1989) model.

The observed and predicted location of the equatorward boundary of the radar backscatter during the growth phase coincided most closely from 04:35 to 05:50 UT (Fig. 7), and, therefore, we concentrate on the modelled location of radar backscatter calculated for this interval. The upstream WIND data gives the average instantaneous electric field across the dayside magnetopause as $0.26 \pm 0.10 \mathrm{mV} / \mathrm{m}$, the potential across the dayside magnetopause is then $60 \pm 35 \mathrm{kV}$. Assuming no field-aligned potential drop, the reconnection potential across the dayside magnetopause will be equal to the reconnection potential across the ionospheric merging gap. The Tsyganenko 89 (Tsyganenko, 1989) model was used to map the magnetospheric electric field to the ionosphere, giving the average electric field along the dayside merging gap as $22 \pm 10 \mathrm{mV} / \mathrm{m}$ in its own rest frame. The substorm growth phase actually lasts from 04:35 to 06:13 UT, assuming the expansion of the polar cap is constant throughout this interval; the polar cap expands by $\sim 6.5 \times 10^{6} \mathrm{~km}^{2}$ during the growth phase, with an average magnetic flux addition rate of $\sim 5 \times 10^{4} \mathrm{~Wb} / \mathrm{s}$.
4.2 Measuring the length and electric field of the dayside merging gap using dayside observations

As already mentioned in the Introduction, reconnection on the dayside is related to the creation of open flux and the subsequent expansion of the polar cap area, while reconnection on the nightside destroys open flux and leads to the contraction of the polar cap area. Both dayside and nightside reconnection are thus related to flow across the dayside and nightside merging gaps. The (poleward) boundary-normal plasma flow velocity across the dayside or nightside merging gap is given by (Lockwood et al., 1993):

$V_{B}=V_{C}-V^{\prime}$

where $V_{B}$ is the boundary-normal velocity, $V_{C}$ is the boundary-normal plasma flow velocity across the merginggap in the Earth's frame, and $V^{\prime}$ is the poleward velocity of the ionospheric projection of the $X$-line in the reference frame of the Earth.

We calculated the flow across the dayside merging gap during the substorm growth phase, concentrating on the interval 04:35 to 05:50 UT, as this was the time interval we studied in detail on the nightside. The DMSP pass presented in Figs. 5 and 6, showed that at 08:06 UT, the open/closed field line boundary was located $\sim 2^{\circ}$ equatorward of the radar backscatter. This DMSP pass is not within the substorm growth phase, and unfortunately, there are no suitable passes during the growth phase period. The IMF conditions at 08:06 UT are similar to the conditions at the end of the growth phase, and there are clear signatures of newly-opened flux at both times. Thus, we are assuming the dayside merg- 
ing gap to be offset from the equatorward boundary of radar backscatter by $2^{\circ}$ for the entire interval studied.

Figure 4 presents the 1-o-s velocity (Fig. 4a) and spectral widths (Fig. 4b) observed on the dayside by the Hankasalmi radar during the interval 04:30 to 08:30 UT. During the interval of the substorm growth phase (04:35 to 06:13 UT), the anti-sunward moving ionospheric backscatter is associated with high spectral widths. Previous studies have associated such high-latitude, high spectral widths with open field lines, and lower latitude, lower spectral widths with closed field lines (Baker et al., 1990, 1995; Provan et al., 1998). A black and white line has been drawn on Fig. 4b, marking the equatorward edge of the high spectral width region during the substorm growth phase; this line will be used as a proxy for the open/closed field line boundary.

Between 04:35 and 05:50 UT, the equatorward edge of the polar cap boundary moves equatorward at a velocity of $95 \pm 30 \mathrm{~m} / \mathrm{s}$. Using a beam-swinging technique, which assumed L-shell aligned plasma flow, the beam-swung plasma flow velocity was derived at $1^{\circ}$ latitude intervals. Averaging over all latitudes, the poleward component of the beam-swung velocities averaged for the interval 04:35 to 05:50 UT was $185 \pm 95 \mathrm{~m} / \mathrm{s}$. From Eq. (3), the boundarynormal plasma flow velocity across the dayside merging gap is then $280 \pm 100 \mathrm{~m} / \mathrm{s}$ in a poleward direction.

The laws of magnetohydrodynamics state that if the magnetized plasma is assumed to be a fluid whose conductivity is so large that there is no diffusion of the electric field, the velocity of the fluid, $\boldsymbol{v}$, is governed by the equation:

$\boldsymbol{E}=\boldsymbol{v} \times \boldsymbol{B}$.

Taking $\boldsymbol{B}$ to be the polar ionospheric magnetic field, $B_{p}$, we calculate the electric field across the dayside merging gap to be equal to $14 \pm 5 \mathrm{mV} / \mathrm{m}$.

As stated previously, pulsed ionospheric flows (PIFs) are believed to be the ionospheric signature of the transfer of newly-reconnected flux. We have attempted to measure the azimuthal extent of an individual PIF in the high-latitude ionosphere to approximate the length of the dayside merging gap. Unfortunately, it was impossible to identify individual PIFs during the substorm growth phase. Thus, we have chosen to study a PIF clearly observed by the Hankasalmi radar at 08:10 UT, a time when the IMF conditions at the subsolar magnetopause ( $B_{y}=3.5 \mathrm{nT}, B_{z}=-5 \mathrm{nT}$ ) were quite similar to the IMF conditions at the subsolar magnetopause at the end of the substorm growth phase ( $B_{y}=4.6 \mathrm{nT}, B_{z}=-3.8 \mathrm{nT}$ ).

Figure 9 presents the polar plots from Hankasalmi and Iceland West, 16/09/98, for 08:10 UT. In studying 1-o-s velocity from the two radars, we can conclude that strong antisunward flow is observed over $\approx 7 \mathrm{~h}$ of magnetic local time. Two solid black lines mark the edges of the merging gap; these lines are joined together with a curved black line, representing the estimated MLT extent of the merging gap (not its latitudinal position). A dayside merging gap, covering at least $7 \mathrm{~h}$ of MLT, together with the E-field calculations above, results in a potential across the dayside merging gap of $35 \pm 15 \mathrm{kV}$. We utilized the Tsyganenko 89 model to map the dayside merging gap out to the dayside magnetopause, calculating that if the dayside merging gap covered $7 \mathrm{~h}$ of magnetic local time, the magnetopause $X$-line length would be $35 \pm 15 R_{E}$.

\subsection{Measuring the potential across the dayside merging gap using the map-potential technique}

The cross polar-cap potential is an important indication of the rate of energy transfer from the solar wind to the Earth's magnetosphere. The map-potential technique produces global convection maps, solved by fitting velocity data to an expansion of the electrostatic potential in terms of spherical harmonic functions. Shepherd and Ruohoniemi (2000) stated that when there were extensive radar measurements of 1-o-s velocity, and especially when they span the extrema in the potential distributions, the solution for the global pattern becomes insensitive to the choice of statistical model data used to constrain the data. The cross polar-cap potential (dawnto-dusk transpolar voltage), as defined by the map-potential technique, is equal to the potential difference between the maximum and minimum voltages of the dawn and dusk convection cells.

Figure 10 presents a schematic illustration of the magnetosphere for southward IMF (Lockwood and Cowley, 1992). Open field lines are generated at the $X$-line on the dayside magnetopause. Neglecting any field-aligned voltages, then $\Phi_{D}^{\prime}$ is the voltage across the dayside $X$-line length (AB) in its own rest frame and also the voltage across the dayside merging gap in the ionosphere $(a b)$ in its own rest frame. Likewise, reconnection in the tail neutral sheet destroys open flux at a rate $\Phi_{N}^{\prime}$, the rest frame voltage across the nightside $X$-line $\mathrm{DE}$ and its corresponding ionospheric merging gap de.

As described before, Figs. 1a and $1 \mathrm{~b}$ illustrate the dayside $\left(\Phi_{D}\right)$, nightside $\left(\Phi_{N}\right)$ and cross polar cap $\left(\Phi_{P C}\right)$ potentials in the reference frame of the Earth, for intervals of steady, balanced dayside and nightside reconnection, and unbalanced dayside reconnection, respectively. The area of the polar cap, the region threaded by open magnetic flux, changes due to dayside and nightside reconnection; hence, its boundaries move in the Earth's reference frame. The potentials across the dayside or nightside merging gaps in the reference frame of the Earth are then not equal to the potential across the dayside or nightside merging gaps in their own reference frames. Siscoe and Huang (1985) assumed a circular polar cap. In this case the average cross polar cap potential in the reference frame of the Earth is:

$\Phi_{P C}=\Phi_{V}+\frac{\Phi_{D}+\Phi_{N}}{2}$,

where $\Phi_{V}$ is the potential due to any viscous-like interaction.

The above equation describes well the situation illustrated in Fig. 1a, where balanced dayside and nightside reconnection results in steady flow over the poles, and the cross polarcap potential is equal to the average value of the potential across the dayside and nightside merging gaps (plus any con- 


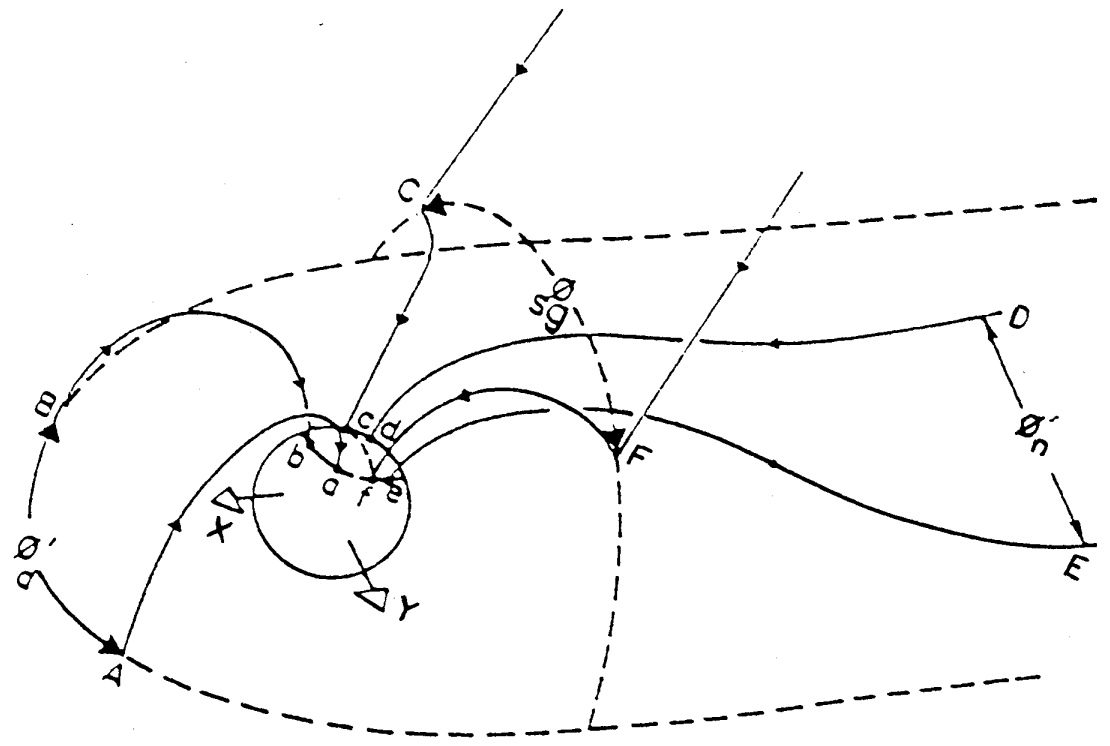

Fig. 10. Schematic illustration of the magnetosphere for southward IMF (Lockwood and Cowley, 1992). tribution from viscous interaction). Figure $1 \mathrm{~b}$ shows the convective flows and cross polar-cap potential initiated during the substorm growth phase. Such a cross polar-cap potential for an interval of unbalanced dayside reconnection cannot be satisfactorily described by Eq. (5). The cross polar-cap potential, as defined by the map-potential technique for this situation, however, is equal to the potential difference between the maximum and minimum voltages of the dawn and dusk convection cell. Thus, we assume that during the substorm growth phase, the cross polar-cap potential is equal to the potential across the dayside merging gap.

The solid dark line on Fig. 11 presents the cross polar-cap potential as calculated by the map-potential technique for the interval 00:00 to 09:00 UT. As before, the IMF conditions were given by the WIND spacecraft; the electrostatic potential was expanded to an order of 8 , and the flow was assumed to be centered $4^{\circ}$ from the pole, with the low-latitude limit of the convection zone assumed to be at $70^{\circ}$. The map-potential technique derives the cross polar-cap potential, using both the observed ionospheric velocities and a statistical model based on the IMF conditions. The error in the potential is related to the extent on which the potential is dependent on the statistical model; a high level of dependency would result in a highly averaged value for the potential.

To derive an estimate of the error in the potential, we have re-calculated the cross polar-cap potential. This time, instead of the IMF information being given by the WIND spacecraft, we have assumed that the IMF $B_{z}$ component is constantly negative (between -6 to $-12 \mathrm{nT}$, presented as a dashed line on Fig. 11), and $B_{z}$ constantly positive (between 0 to $4 \mathrm{nT}$, presented as a dot-dashed line in Fig. 11). These three potential estimates follow the same curve (obviously defined by the observed data), but the difference in the cross polar-cap potential can vary by up to $40 \mathrm{kV}$ from the $B_{z}$ positive to $B_{z}$ negative estimates. We have averaged the cross polar-cap potential during the interval 02:00 to 03:00 UT when the IMF
$B_{z}$ component is positive, and during the substorm growth phase interval of 04:35 to 06:15 UT. From Fig. 11 it can be seen that all three cross polar-cap potentials increase during the growth phase, as compared with the interval 02:00 to 03:00 UT. The average value of the potential calculated using the observed IMF conditions increased by $21 \mathrm{kV}$ during the growth phase; the cross polar-cap potential derived assuming a constant $B_{z}$ positive increased by $19 \mathrm{kV}$, while the cross polar-cap potential derived assuming a constant $B_{z}$ negative increased by $16 \mathrm{kV}$. The similarity of the increase in the cross polar-cap potential during the substorm growth phase demonstrates that for this interval, the potential is driven by ionospheric plasma flows and not by the statistical model. The difference in the increase in the potential between the three estimates of the cross polar-cap potential can be used to derive an estimate of the error in the potential measurement; thus, we assume an error in the cross polar-cap potential of $5 \mathrm{kV}$.

The start (04:35 UT) and end (06:13 UT) times of the substorm growth phase are marked on the plot with vertical dashed lines. We averaged the cross polar-cap potential for the entire interval of the growth phase, giving us a value of $60 \pm 10 \mathrm{kV}$. The next step was to predict the contribution of viscous interaction to the total potential. We assumed the cross polar-cap potential during extended intervals of northward IMF to be equal to the viscous potential. The IMF $B_{z}$ component was at its most northernly between 02:20 and 02:47 UT (Fig. 3), with the average $\Phi_{P C}$ during this interval at $35 \pm 6 \mathrm{kV}$. Thus, we assumed that of the initial cross $p c$ potential during the substorm growth phase of $60 \mathrm{kV}, 25 \pm 6 \mathrm{kV}$ is due to dayside reconnection, and this is the potential across the dayside merging gap. Assuming (as in Sect. 4.2) that the electric field across the dayside merging gap is $14 \pm 5 \mathrm{mV} / \mathrm{m}$, this would result in a dayside merging gap of $5 \pm 2 \mathrm{~h}$ of MLT. We used the Tsyganenko 89 model to calculate that if the dayside merging gap covered $5 \pm 2 \mathrm{~h}$ of magnetic local time, 


\section{Cross polar-cap potential, 16/09/98, 00:00-09:00 UT}

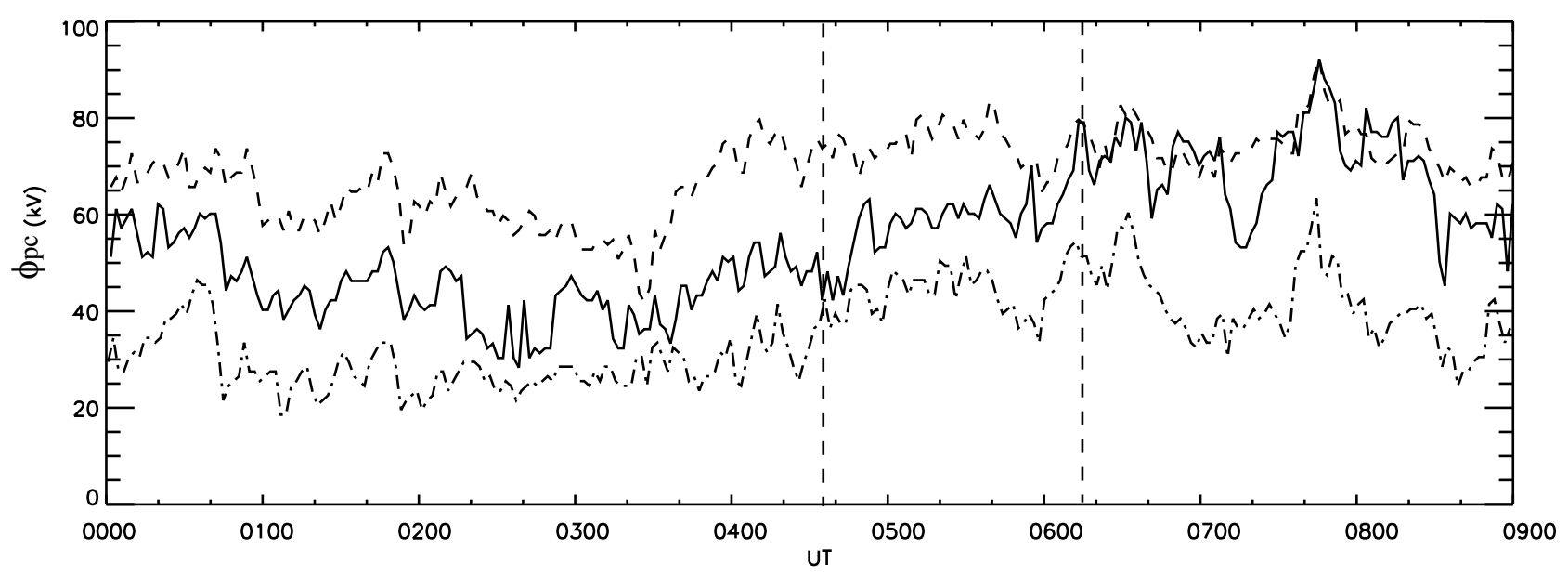

Fig. 11. The cross polar-cap potential estimated by the map-potential technique for the interval 16 Sept. 1998, 00:00-09:00 UT, IMF information was given by the WIND satellite (black line). Overlaid is the cross polar-cap potential assuming constant $B_{z}$ negative (dashed line), and $B_{z}$ positive (dot-dashed line).

the magnetopause $X$-line length would be $30 \pm 12 R_{E}$.

These values of the extent and potential across the dayside merging gap are smaller than those estimated using the previous two methods, although still within the error ranges. They have probably been underestimated because we have overestimated the contribution that viscous interaction makes to the cross polar-cap potential. When the cross polar-cap potential is measured during a prolonged period of northward IMF, it tends to decrease with time. A value of $\sim 10-20 \mathrm{kV}$ for the viscous potential has been confirmed by several independent observations (Eastman and Hones, 1979; Saunders, 1990; Mozer, 1984; Lundin and Evans, 1985; Lu et al., 1994). Also, individual maps of ionospheric convection during the substorm growth phase clearly support an extended merging region. Studying Fig. 8 around local noon demonstrates that measuring the cross polar-cap potential from, for example 10 to 14 MLT, across the polar cap, would still not include a significant portion of the cross polar-cap potential, clearly indicating that a significant contribution to the cross polar-cap potential must come from merging occurring far from noon.

\section{Summary}

We have presented observations of high-latitude plasma flow using data from six of the Northern Hemisphere SuperDARN radars. The data provided a unique opportunity to examine the time-dependent nature of the coupling between the solar wind, magnetosphere and ionosphere over $12 \mathrm{~h}$ of MLT. A substorm growth phase and expansion phase onset was identified on the nightside, and simultaneous signatures of newlyreconnected flux were detected on the dayside. During the substorm growth phase, the pre-midnight polar cap boundary was found to be adiaroic, as has previously been predicted by Cowley and Lockwood (1992). Combining the HF radar observations with WIND, DMSP and magnetometer data, and global ionospheric convection maps, allowed us to estimate the global merging rate using three different methods. A single merging $X$-line and uniform merging field were assumed.

Two methods were used to estimate the electric field along the dayside merging gap. SuperDARN observation of dayside high-latitude plasma flow suggests an electric field along the dayside merging gap of $14 \pm 5 \mathrm{mV} / \mathrm{m}$. Upstream solar wind data from the WIND spacecraft has been used to calculate an average electric field along the dayside merging gap during the substorm growth phase of $22 \pm 10 \mathrm{mV} / \mathrm{m}$ (Sonnerup, 1974; Hill, 1975). This is almost twice the electric field derived using the dayside data, although the error range for the calculations is large. Previous estimates of the reconnection electric field have been made by de la Beujardiere et al. (1991). These workers used data from the Sonderestrom incoherent scatter radar to predict a reconnection electric field of $15 \mathrm{mV} / \mathrm{m}$ during the subsorm expansion phase and an electric field of 30 to $40 \mathrm{mV} / \mathrm{m}$ during the recovery phase. These estimates, although not derived during the growth phase, are within the same order of magnitude as our calculations.

The electric field calculated from the WIND measurements was used to model the equatorward boundary of the polar cap during the substorm growth phase (Lewis et al., $1998 \mathrm{~b}$ ), giving a dayside magnetopause $X$-line of $35 \pm 15 R_{E}$, equivalent to $7 \pm 3 \mathrm{~h}$ of magnetic local time. Calculations based on dayside radar observations gave an identical value for the dayside magnetopause $X$-line length. Estimates using the cross polar potential derived from the map-potential 
model results yielded in a magnetopause $X$-line length of $30 \pm 12 R_{E}$. This value is smaller than the two other estimates of $X$-line length, although well within the error ranges. We believe that it is an underestimate of the true value of the $X$ line length, probably due to the contribution of viscous interaction to the cross polar-cap potential being overestimated.

It is perhaps surprising that the approximate $X$-line length is so similar when deduced from the three techniques, especially since the ionospheric electric field deduced from the upstream solar wind data is nearly twice that deduced from the dayside ionospheric data. However, the calculations based upon the upstream solar wind data and the nightside ionospheric data (the technique of Lewis et al., 1998) has two major assumptions: it is assumed that the motion of the equatorward boundary accurately tracks the polar cap expansion, but no account of field line stretching in the tail is made. However, from studying the difference in the polar cap expansion rate on the dayside $(95 \pm 30 \mathrm{~m} / \mathrm{s})$, as compared with the nightside $(140 \pm 30 \mathrm{~m} / \mathrm{s})$, it is clear that the tail field lines are stretched. It is also assumed that the calculation of the upstream electric field is an accurate estimate of the magnetosheath field applied to the dayside magnetopause. However, the actual magnetosheath electric field will depend upon the diversion of the solar wind around the magnetosphere, which determines the distortion of the equipotential solar wind streamlines. It appears that shortcomings in these two assumptions combine to give a reasonable estimate of the $X$-line length.

The length of the dayside $X$-line is not well known. Russell and Elphic $(1978,1979)$ originally suggested a value of $1 R_{E}$, but other workers have subsequently argued that the length of the $X$-line is likely to be longer (Lee and Fu, 1985; Scholer, 1988; Southwood et al., 1988). Previous workers have also used the method of Lewis et al. (1998b) to derive lengths of the dayside magnetopause $X$-line of $12 R_{E}$ (Lewis et al., 1998b) and $27 R_{E}$ (Yeoman et al., 1999). The findings presented in this paper, thus, support the belief of an extensive $X$-line length, as well as giving us added confidence when using the methods outlined in this paper in future work. Additional future work will include studying the variation in the length of the magnetopause $X$-line length with solar wind and IMF conditions.

Acknowledgements. CUTLASS is supported by the Particle Physics and Astronomy Research Council (PPARC grant PPA/R/R/1997/00 256). U.K., the Swedish Institute for Space Physics, Uppsala, and the Finnish Meteorological Institute. Helsinki. GP is supported by PPARC grant PPA/G/O/1999/00 181. The authors wish to thank the Canadian Space Agency for providing the CANOPUS data, G. Sofko for providing HF radar data from the Saskatoon radar, P. T. Newell for providing DMSP data and R. A. Greenwald, J. M. Ruohoniemi and R. Barnes for providing the map-potential software. We are grateful to Ron Lepping and Keith Ogilvie, principal investigators on the WIND spacecraft MFI and SWE instruments respectively.

The Editor in chief thanks C. I. Meng and G. Chisham for their help in evaluating this paper.

\section{References}

Baker, K. B. and Wing, S.: A new magnetic coordinate system for conjugate studies of high-latitude, J. Geophys. Res., 94, 91399143, 1989.

Baker, K. B., Greenwald, R. A., Ruohoniemi, J. M., Dudeney, J. R., Pinnock, M., Newell, P. T., Greenspan, M. E., and Meng, C.I.: Simultaneous HF-radar and DMSP observations of the cusp, Geophys. Res. Lett., 17, p1869, 1990.

Baker, K. B., Dudeney, J. R., Greenwald, R. A., Pinnock, M., Newell, P. T., Rodger, A. S., Mattin, N., and Meng, C.-I.: HF radar signatures of the cusp and low-latitude boundary layer, J. Geophys. Res., 100, p7671, 1995.

Cowley, S. W.H. and Lockwood, M.: Excitation and decay of solar wind-driven flows in the magnetosphere-ionosphere system, Ann. Geophysicae, 10, p103, 1992.

De La Beaujardiere, O., Lyons, L. R., and Friis-Christensen, E.: Sondrestrom radar measurements of the reconnection electric field, J. Geophys. Res., 96, 13 907-13 912, 1991.

Dungey, J. W.: Interplanetary field and the auroral zones, Phys. Res. Lett., 47-48, 1961.

Eastman, T. E. and Hones, E. W. Jr.: Characteristics of the magnetospheric boundary layer and the magnetopause as observed by Imp 6, J. Geophys. Res., 84, p2019, 1979.

Greenwald, R. A., Baker, K. B, Dudeney, J. R. et al.: DARN/SUPERDARN: A global view of high-latitude convection, Space Sci. Rev., 71, 763-796, 1995.

Hardy, D. A., Schmitt, L. K., Gussenhoven, M. S., Marshall, F. J., Yeh, H. C., Shumaker, T. L., Hube, A., and Pantazis, J.: Precipitating electron and ion detectors (SSJ/4) for the block 5D/flights 6-10 DMSP satellites: Calibration and data presentation, Rep. AFGL-TR-84-0317, Air Force Geophys. Lab, Hanscom Air Force Base, Mass., 1984.

Hill, T. W.: Magnetic merging in collisonless plasma, J. Geophys. Res., 80, p4689, 1975.

Holzworth, R. H. and Meng, C.-I.: Mathematical representation of the auroral oval, Geophys. Res. Lett, 2, p377, 1975.

Lee, L. C. and Fu, Z. F.: A theory of magnetic flux transfer at the Earth's magnetopause, Geophys. Res. Lett., 2, p377, 1985.

Lepping, R. P., Acuna, M. H., Burlage, L. E. et al.: The WIND magnetic field investigation, Space. Sci. Rev., 71, 207-229, 1995.

Lester, M.: HF coherent scatter radar observations of ionospheric convection during magnetospheric substorms, Adv. in Polar Upper Atmosphere Research, 12, p179, 2000.

Lester, M., de la Beujardière, O., Foster, J. C., Freeman, M. P., Lühr, H., Ruohoniemi, J. M., and Swider, W.: The response of the large-scale ionospheric convection pattern to changes in the IMF and substorms: Results from the SUNDIAL 1987 campaign, Ann. Geophysicae, 11, 556-571, 1993.

Lewis, R. V., Freeman, M. P., Rodger, A. S., Reeves, G. D., and Milling, D. K.: The electric field response to the growth phase and expansion phase onset of a small expansion phase onset of a small isolated substorm, Ann. Geophys., 15, p289, 1997.

Lewis, R. V., Freeman, M. P., Rodger, A. S., Watanabe, M., and Greenwald, R. A.: The behaviour of the electric field within the substorm current wedge, J. Geophys. Res., 103, p179, 1998a.

Lewis, R. V., Freeman, M. P., and Reeves, G. D.: The relationship between HF radar backscatter to the accumulation of open magnetic flux prior to substorm onset, J. Geophys. Res., 103, p26 623, 1998b. 
Lockwood, M., Sandholt, P. E., Farmer, A. D., Cowley, S. W. H., Lybekk, B., and Davda, V. N.: Auroral and plasma flow transients at magnetic noon, Planet. Space. Sci., 38, 973-993, 1990.

Lockwood, M.: On flow reversal boundaries and cross-cap potential in average models of the high-latitude convection, Planet. Space Sci., 39, p397, 1991.

Lockwood, M. and Cowley, S. W. H.: Ionospheric Convection and the substorm cycle, in Substorms 1, Proceedings of the first International Conference on Substorms, ICS-1, Ed. C. Mattock, ESA-SP-335, European Space Agency Publications, Norvijk, The Netherlands, 99-110, 1992.

Lockwood, M., Moen, J., Cowley, S.W.H., Farmer, A. D., Løvhaug, U. P., Lühr, H., and Davda, V. N.: Variability of the dayside convection and motion of the cusp/cleft aurora, Geophys. Res. Lett., 20, 1011-1014, 1993.

Lockwood, M. and Davis, C. J.: On the longitude extent of the magnetopause reconnection pulse, Ann. Geophys., 14, 865-878, 1996.

Lu, G., Richmond, A. D., Emery, B. A. et al.: Interhemispheric asymmetry of the high-latitude ionospheric convection pattern, J. Geophys. Res. 99, 6491-6510, 1994.

Lundin, R. and Evans, D. S.: Boundary layer plasma as a source for high-latitude, early afternoon, auroral arcs, Planet. Space. Sci., 32, p1389, 1985.

McWilliams, K. A., Yeoman, T. K., and Provan, G.: A statistical survey of dayside pulsed ionospheric flows as seen by the CUTLASS Finland HF radars, Ann. Geophys., 4, 445-453, 2000.

Milan, S. E., Jones, T. B., Lester, M., Warrington, E. M., and Reeves, G. D.: Substorm correlated absorption on a $3200 \mathrm{~km}$ trans-auroral HF propagation path, Ann. Geophys., 14, p182, 1996.

Morelli, J. P., Bunting, R. J., Cowley, S. W. H., Farrugia, C. J., Freeman, M. P., Friis-Christensen, E., Jones, G. O. L., Lester, M., Lewis, R. V., Lühr, H., Orr, D., Pinnock, M., Williams, P. J. S., and Yeoman, T. K.: Radar observations of auroral-zones flows during a multiple-onset substorm, Ann. Geophys., 13, 11441163, 1995.

Mozer, F. S.: Electric field evidence on the viscous interaction at the magnetopause, Geophys. Res. Lett., 11, p135, 1984.

Neudegg, D. A., Yeoman, T. K., Cowley, S. W. H., Provan, G., Haerendel, G., Baumjohann, W., Auster, U., Fornacon, K.-H., Georgescu, E., and Owen, C. J.: A flux transfer event observed at the magnetopause by the Equator-S spacecraft and in the ionosphere by the CUTLASS HF radar, Ann. Geophys., 17, 707-711, 1999.

Neudegg, D. A., Cowley, S.W.H., Milan, S. E., Yeoman, T. K., Lester, M., Provan, G., Haerendel, G., Baumjohann, W., Nikutowski, B., Buchner, J., Auster, U., Fornacon, K.-H., and Georgescu, E.: A survey of magnetopause FTEs and associated flow bursts in the polar ionosphere, Ann. Geophys., 18, 416-435, 2000.

Provan, G. and Yeoman, T. K.: Statistical observations of the MLT, latitude and size of pulsed ionospheric flows with the CUTLASS Finland radar, Ann. Geophys., 17, 855-867, 1999.

Provan, G., Yeoman, T. K., and Milan, S. E.: CUTLASS Finland Radar observations of the Ionospheric Signatures of Flux Transfer Events and the Resulting Plasma Flows, Ann. Geophys., 16, 1411-1422, 1998.

Rijnbeek, R. P., Cowley, S. W. H., Southwood, D. J., and Russell, C. T.: A survey of dayside flux transfer events observed by the ISEE-1 and -2 magnetometers, J. Geophys. Res., 89, 786-800, 1984.
Ruohoniemi, J. M. and Baker, K. B.: Large-scale imaging of highlatitude convection with Super Dual Auroral Radar Network HF radar observations, J. Geophys. Res., 103, 20 797-20 811, 1998.

Ruohoniemi, J. M. and Greenwald, R. A.: Statistical patterns of high-latitude convection obtained from the Goose Bay HF radar observations, J. Geophys. Res., 101, 21 743-21 763, 1996.

Ruohoniemi, J. M., Greenwald, R. A., Baker, K. B., Baker, K. B., Villain,, Hanuise, C., and Kelley, J.: Mapping high-latitude plasma convection with coherent HF radars, J. Geophys. Res., 94, p3463, 1989.

Russell, C. T.: The configuration of the magnetosphere, in Critical Problems of Magnetospheric Physics, edited by E. R. Dyer, National Academy of Sciences, Washington, D.C., 1972.

Russell, C. T. and McPherron, R. L.: Semi-annual variation of Geomagnetic Activity, J. Geophys. Res., 78, 92-108, 1973.

Russell, C. T. and Elphic, R. C.: Initial ISEE magnetometer results: Magnetopause observations, Space Sci. Rev., 22, p681, 1978.

Russell, C. T. and Elphic, R. C.: ISEE observations of flux transfer events at the dayside magnetopause, Geophys. Res. Lett, 6, p33, 1979.

Saunders, M. A.: Magnetosheath, magnetopause and low-latitude boundary layer research, 1987-1989, J. Atmos. Terr. Phys., 52, p1107, 1990.

Scholer, M.: Magnetic flux transfer at the magnetopause based on a single $X$ line bursty reconnection, J. Geophys. Res., 15, 291294, 1988.

Shand, B. A., Yeoman, T. K., Lewis, R. V., Greenwald, R. A., and Hairston, M. R.: Inter-hemispheric contrasts in the ionospheric convection response to changes in the Interplanetary Magnetic Field and substorm activity: A case study, Ann. Geophys., 17, p764, 1998.

Shepherd, S. G. and Ruohoniemi, J. M.: Electrostatic potential patterns in the nigh-latitude ionosphere constrained by the SuperDARN measurements, J. Geophys. Res., 105, 23 005-23 014, 2000.

Siscoe, G. L. and Huang, T. S.: Polar cap inflation and deflation, J. Geophys. Res., 90, 543-547, 1985.

Sonnerup, B. U. Ö.: Magnetopause reconnection rate, J. Geophys. Res., 79, p1546, 1974.

Southwood, D. J., Farrugia, C. J., and Saunders, M. A.: What are flux tranfer events, Planet. Space Sci., 36, p503, 1988.

Taylor, J. R., Yeoman, T. K., Lester, M., Emery, B. A., and Knipp, D. J.: Variations in the polar cap area during intervals of substorm activity on 20-21 March 1990 deduced from AMIE convection patterns, Ann. Geophys., 14, 879-887, 1996.

Taylor, J. R., Lester, M., Yeoman, T. K., Greenwald, R., Sofko, G., and Villain, J.-P.: Ionospheric convection response to a northward turning of the interplanetary magnetic field on 23 March 1995 studied employing SuperDARN radar data, Adv. Space Res., 22, 1289-1292, 1998.

Taylor, J. R., Cowley, S. W. H., Yeoman, T. K., Lester, M., Jones, T. B., Greenwald, R. A., Sofko, G., Villain, J.-P., Lepping, R. P., and Hairston, M. R.: SuperDARN studies of ionospheric convection response to a northward turning of the interplanetary magnetic field, Ann. Geophys., 16, 549-565, 1998.

Tsyganenko, T. A.: A magnetopsheric magnetic field model with a warped tail current sheet., Planet Space Sci., 37, 5-10, 1989.

Villain, J. P., Greenwald, R. A., Baker, K. B., and Ruohoniemi, J. M.: HF radar observations of E-region plasma irregularities produced by oblique electron streaming, J. Geophys. Res., 92, 12 327-12 342, 1987.

Yeoman, T. K. and Pinnock, M.: The high-latitude convection re- 
sponse to an interval of substorm activity, Ann. Geophys., 14, 518-530, 1996.

Yeoman, T. K. and Lühr, H.: CUTLASS/IMAGE observations of high-latitude convection features during substorms, Ann. Geophys., 15, p692, 1997.

Yeoman, T. K., Lester, M., Cowley, S. W. H., Milan, S. E., Moen, J., and Sandholt, P. E.: Simultaneous observations of the cusp in optical, DMSP and HF radar data, Geophys. Res. Lett., 24, 2251-2254, 1997.

Yeoman, T. K., Lewis, R. V., Milan, S. E., and Watanabe, M.: An interhemispheric study of the ground magnetic and ionospheric electric field during the substorm growth phase and the expansion phase onset, J. Geophys. Res., 104, 14 867-14 877, 1999. 